\title{
POLYPHENOLS PROFILE AND ANTIOXIDANT ACTIVITY OF SOME ROMANIAN RANUNCULUS SPECIES
}

\author{
TEODORA NEAG ${ }^{\mathrm{a}}$, CLAUDIA-CRINA TOMA $^{\mathrm{a}}$, NELI OLAH ${ }^{\mathrm{a}, \mathrm{b}}$ *, \\ AUREL ARDELEAN ${ }^{a}$
}

\begin{abstract}
The Ranunculus species are mostly known for their toxic effect due to the anemonine and protoanemonine content. This paper studies the polyphenols and the antioxidant activity of four different spontaneous species from Ranunculus genus (Ranunculaceae family) harvested from Western Romania's spontaneous flora. The polyphenols profile was established by TLC and UV-Vis spectrophotometric methods. The antioxidant capacity was evaluated by different in vitro methods: DPPH, TEAC, FRAP, CUPRAC and SNP. From the studied species were prepared two different extracts: hydroalcoholic extracts (HA) respectively glycerol-ethanol extracts (GE). The study indicates that the highest total flavonoid content is in R. ficaria herb HA extract $(23 \% \mathrm{mg} / \mathrm{ml})$, while the total phenolic acids are the highest in $R$. bulbosus herb GE extract $(14,88$ $\% \mathrm{mg} / \mathrm{ml})$. The most important antioxidant activity was observed at GE extracts obtained from herb of $R$. ficaria, $R$. sardous and $R$. bulbosus. With the less antioxidant effect are the $R$. sceleratus extracts.
\end{abstract}

Keywords: Ranunculus ficaria, Ranunculus bulbosus, Ranunculus sardous, Ranunculus sceleratus, antioxidant activity, total flavonoids and total phenolic acids content, rutoside

\footnotetext{
${ }^{a}$ Vasile Goldis Western University of Arad, Faculty of Pharmacy ,86 L. Rebreanu str., RO-310414, Arad, Romania

Corresponding authors: claudiatoma2004@yahoo.com,neliolah@yahoo.com

${ }^{b}$ SC PlantExtrakt SRL, 407059-Rădaia, Jud. Cluj, Romania
} 


\section{INTRODUCTION}

Species of the Ranunculus genus are spread in the aquatic environment, wetlands and meadows. They grow as ornamental plants in parks and gardens or on the waterfront. Almost all species are considered to be toxic, especially during flowering, due to their protoanemonine content. [1,2]

Ranunculus ficaria L. (Ficaria verna Huds.) is a perennial plant that flourishes in the early spring [1]. It is used in folk medicine and in homeopathy for anti-inflammatory, astringent, antibiotic and antihaemorrhagic actions [2]. The tuberous and dry roots of this herbaceous plant with oval, cordate and glossy leaves is used in the pharmacy. Tubers are rich in starch and contain saponosides which are heterosides of hederagenin and oleanolic acid [3]. R. ficaria extracts and $\beta$-cyclodextrin complexes exhibit antioxidant activity even at very low concentrations and could be used in pharmaceutical formulations with improved bioactivity [4]. There are used to treat haemorrhoids by topical application as an ointment or suppositories.

Ranunculus bulbosus $\mathrm{L}$. is used in traditional medicine in gout pain, arthritic pain and neuralgia, being the most used Ranunculus specie in medicine, mainly by its roots. The whole plant has astringent, calming, antispasmodic, diaforetic, rubefiant effects. The chemical constituents present in Ranunculus bulbosus L. are hexadecanoic acid, $\beta$-sitosterol, anemonine and protoanemonine [6].

Ranunculus sardous Crantz has irritating action and is not used in therapy. In the spontaneous flora of Arad county the species Ranunculus sardous grows on halomorphic soils [7].

Ranunculus sceleratus L. has pharmacological effects, such as antibiotic, antiphlogistic, and the relief of articular effusion [8].

The aim of these investigations was to determine the polyphenol profile and antioxidant activity of different Ranunculus extracts using 5 methods: DPPH, FRAP (ferric reducing ability of plasma), TEAC (trolox equivalent antioxidant capacity), CUPRAC (cupric reducing antioxidant capacity) and SNP (silver nanoparticle assay). Herbs have been harvested from the spontaneous flora of the west of Romania, Arad county. Two types of extractive solutions were prepared: mother tinctures (MT) and glycerol macerates (GM). 


\section{RESULTS AND DISCUSSION}

In the figures 1-3 are presented the TLC chromatograms of the studied extracts. There were used chromatographic conditions that separate specifically the polyphenols like flavonoids, phenolic acids, tannins, etc. and it can be observed that all Ranunculus extracts are poor in polyphenols, being separated just 2-4 bands next to the start and immediately below the front. Generally the polyphenols profiles of the extracts are very similar. At $R$. ficaria and $R$. sardous could be observed in HA extracts 1-2 bands more than in GE extracts.

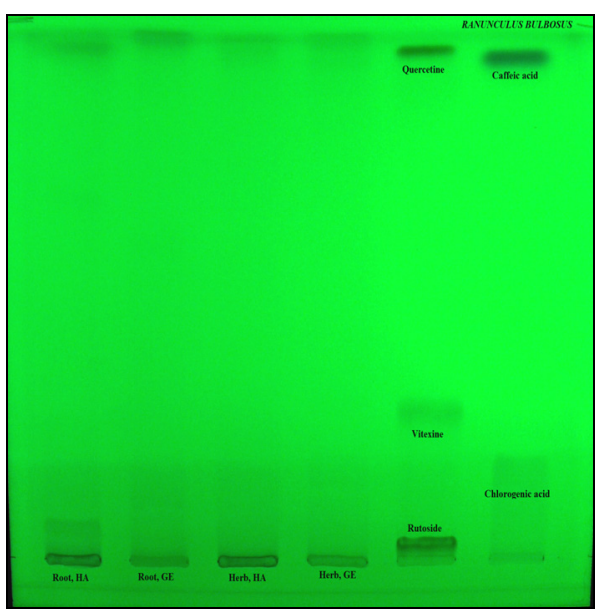

Figure 1. The TLC chromatograms of $R$. bulbosus extracts

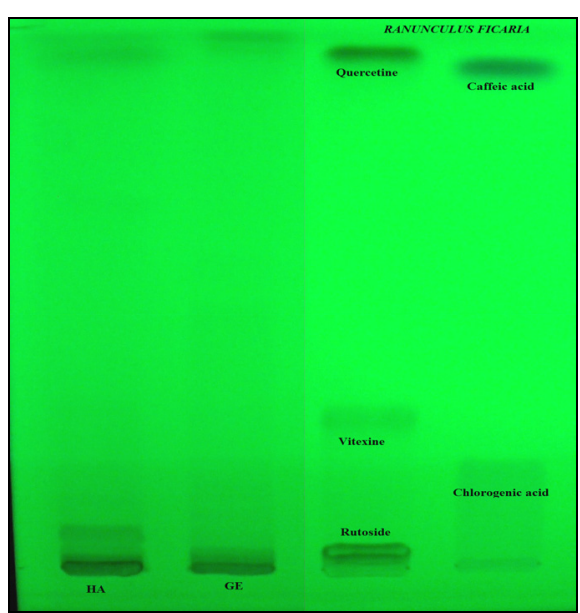

Figure 2. The TLC chromatograms of $R$. ficaria extracts

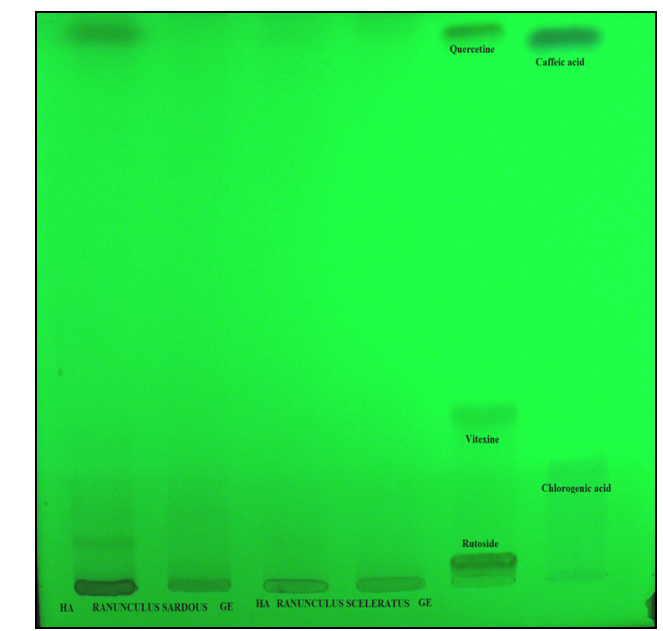

Figure 3. The TLC chromatograms of $R$. sardous and $R$. sceleratus extracts 
In different amounts could be identified the rutoside in all extracts, more intensive bands being in the $R$. bulbosus roots and herba HA extracts respectively in $R$. ficaria herb HA and GE extracts. In $R$. bulbosus extracts can be identified in trace also the chlorogenic acid.

In figures 4 and 5 are presented the calibration curves of rutoside and caffeic acid for total flavonoids and total phenolic acids determination. The calibration curves equations and correlation factors are:

- Rutoside: Absorbance $=0,024 \times$ Concentration $+0,0031, R^{2}=$ 0,9970 .

- Caffeic acid: Absorbance $=0,0534 \times$ Concentration $+0,221, R^{2}=$ 0,9867 .

It can be observed that the highest total phenolic acids content is in GE extracts of $R$. bulbosus roots and herb respectively $R$. sardous, while the $R$. ficaria herb HA respectively $R$. sardous herb HA extracts are the richest in flavonoids (table 1 ).

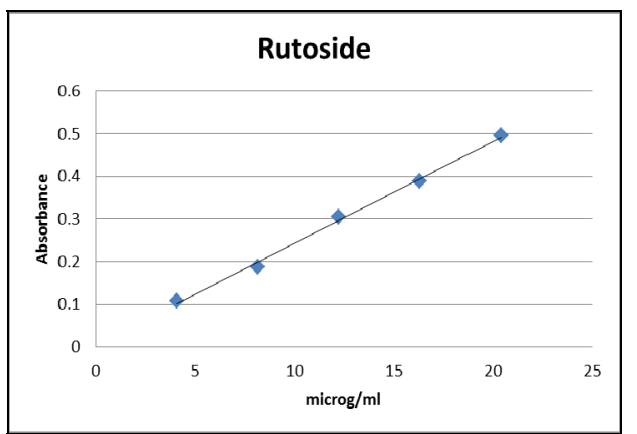

Figure 4. The calibration curve of rutoside

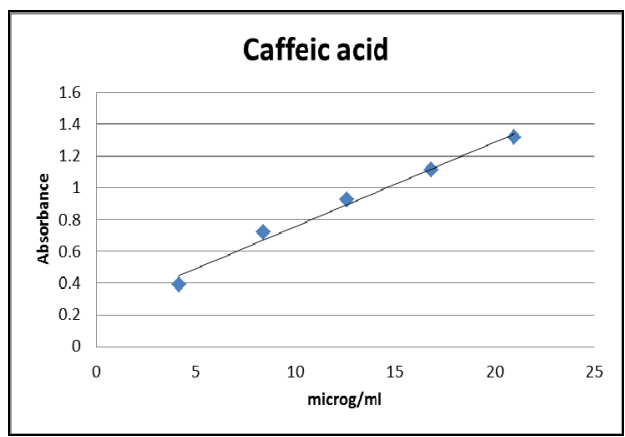

Figure 5. The calibration curve of caffeic acid

These results lead us to conclude that the herb (aerial part) of Ranunculus species is richer in flavonoids. The results can be correlated with the chromatographic analysis result at $R$. ficaria and $R$. sardous where in the region of flavonoids separation are more bands in HA extracts like in GE extracts. The higher phenolic acids content in $R$. bulbosus extract can be also correlated with the identification of chlorogenic acid only in these extracts. 
Table 1. The assays and antioxidant capacity determinations results

\begin{tabular}{|c|c|c|c|c|c|c|}
\hline Extract & \begin{tabular}{|} 
Total flavonoids \\
content, \\
expressed in \\
rutoside \\
$\% \mathrm{mg} / \mathrm{ml}$
\end{tabular} & $\begin{array}{r}\text { Tota } \\
\text { acid } \\
\text { exp } \\
\text { caf } \\
\%\end{array}$ & $\begin{array}{l}\text { al phenolic } \\
\text { s content, } \\
\text { ressed in } \\
\text { ffeic acid } \\
\mathrm{mg} / \mathrm{ml}\end{array}$ & \multicolumn{2}{|c|}{$\begin{array}{c}\mathrm{DPPH}, \mathrm{IC}_{50}, \\
\mu \mathrm{l}\end{array}$} & $\begin{array}{c}\text { TEAC, } \mathrm{IC}_{50}, \\
\mu \mathrm{l}\end{array}$ \\
\hline R. bulb. roots HA & 7.61 & & 9.63 & \multicolumn{2}{|l|}{169.5} & 47.1 \\
\hline R. bulb. roots GE & 0.41 & & 13.44 & \multicolumn{2}{|l|}{180.5} & 71.2 \\
\hline R. bulb. herb HA & 9.34 & & 6.76 & \multicolumn{2}{|l|}{220.1} & 58.3 \\
\hline R. bulb. herb GE & 8.20 & & 14.88 & \multicolumn{2}{|l|}{117.2} & 58.9 \\
\hline R. fic. herb HA & 23.00 & & 5.70 & \multicolumn{2}{|l|}{243.4} & 45.6 \\
\hline R. fic. herb GE & 16.65 & & 11.00 & \multicolumn{2}{|l|}{1.9} & 28.8 \\
\hline R. sard. herb HA & 20.13 & & 8.75 & \multicolumn{2}{|l|}{235.4} & 48.7 \\
\hline R. sard. herb GE & 15.53 & & 13.51 & \multicolumn{2}{|l|}{10.2} & 35.1 \\
\hline R. scel. herb HA & 10.16 & & 0.03 & \multicolumn{2}{|l|}{872.1} & 186.7 \\
\hline R. scel. herb GE & 3.45 & & 1.01 & \multicolumn{2}{|l|}{988.4} & 250.7 \\
\hline & \multicolumn{2}{|c|}{$\begin{array}{c}\text { FRAP, } \\
\mu \mathrm{M} \text { ET/100 ml extract }\end{array}$} & \multicolumn{2}{|c|}{$\begin{array}{c}\text { CUPRAC, } \\
\mu \mathrm{M} \mathrm{ET/100} \mathrm{ml} \mathrm{extract}\end{array}$} & $\mu \mathrm{M} \mathrm{E}$ & $\begin{array}{l}\text { SNP, } \\
\text { T/100 ml extract }\end{array}$ \\
\hline R. bulb. roots HA & \multicolumn{2}{|l|}{150} & \multicolumn{2}{|c|}{155} & & 357 \\
\hline R. bulb. roots GE & \multicolumn{2}{|l|}{178} & \multicolumn{2}{|c|}{259} & & 374 \\
\hline R. bulb. herb HA & \multicolumn{2}{|l|}{160} & \multicolumn{2}{|c|}{188} & & 405 \\
\hline R. bulb. herb GE & \multicolumn{2}{|l|}{163} & \multicolumn{2}{|c|}{278} & & 578 \\
\hline R. fic. herb HA & \multicolumn{2}{|l|}{108} & \multicolumn{2}{|c|}{205} & & 570 \\
\hline R. fic. herb GE & \multicolumn{2}{|l|}{154} & \multicolumn{2}{|c|}{219} & & 596 \\
\hline R. sard. herb HA & \multicolumn{2}{|l|}{129} & \multicolumn{2}{|c|}{195} & & 472 \\
\hline R. sard. herb GE & \multicolumn{2}{|l|}{139} & \multicolumn{2}{|c|}{198} & & 569 \\
\hline R. scel. herb HA & \multicolumn{2}{|l|}{103} & \multicolumn{2}{|c|}{61} & & 297 \\
\hline R. scel. herb GE & \multicolumn{2}{|l|}{60} & \multicolumn{2}{|c|}{49} & & 161 \\
\hline
\end{tabular}

In figures 6-8 are presented the inhibition curves of the extracts by DPPH and TEAC methods respectively for Trolox by FRAP, CUPRAC and SNP methods. The results obtained by different methods for antioxidant activity are presented in table 1. 


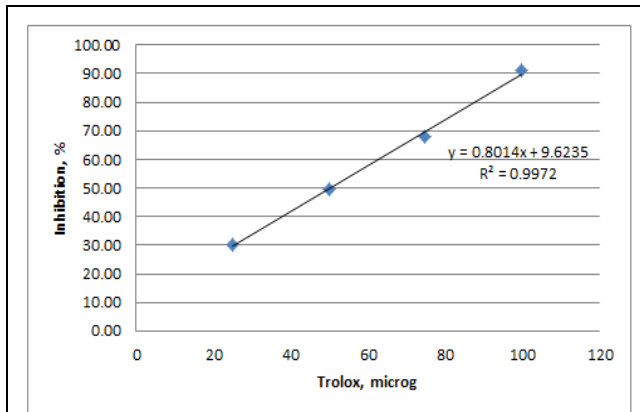

DPPH method

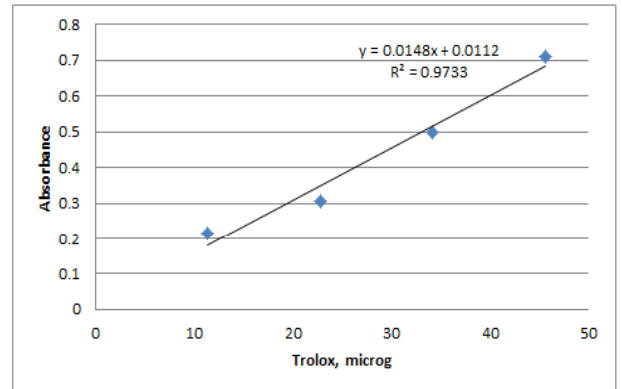

CUPRAC method

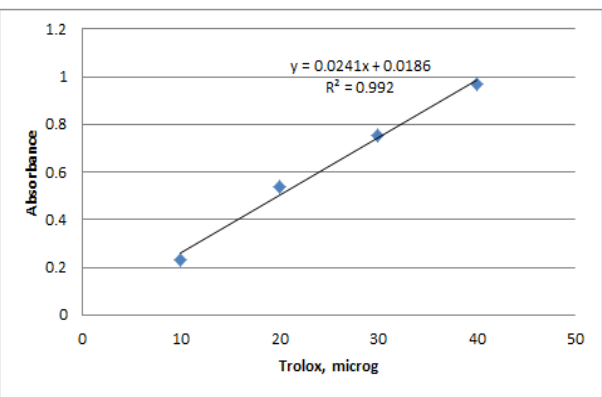

FRAP method

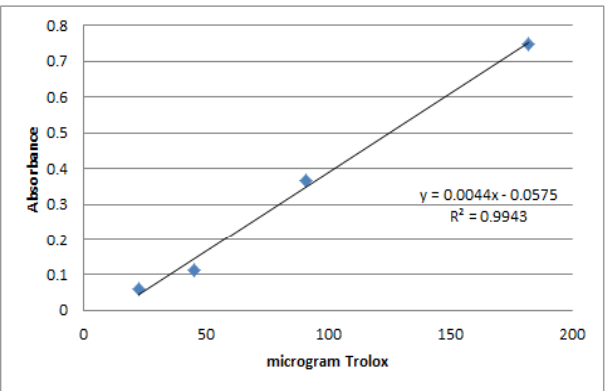

SNP method

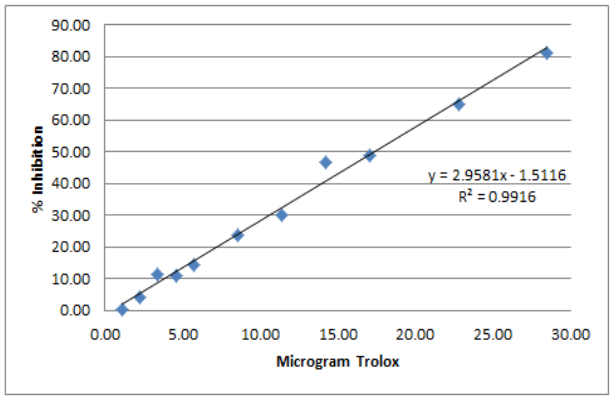

TEAC method

Figure 6. The Trolox inhibition curves obtained by different methods 

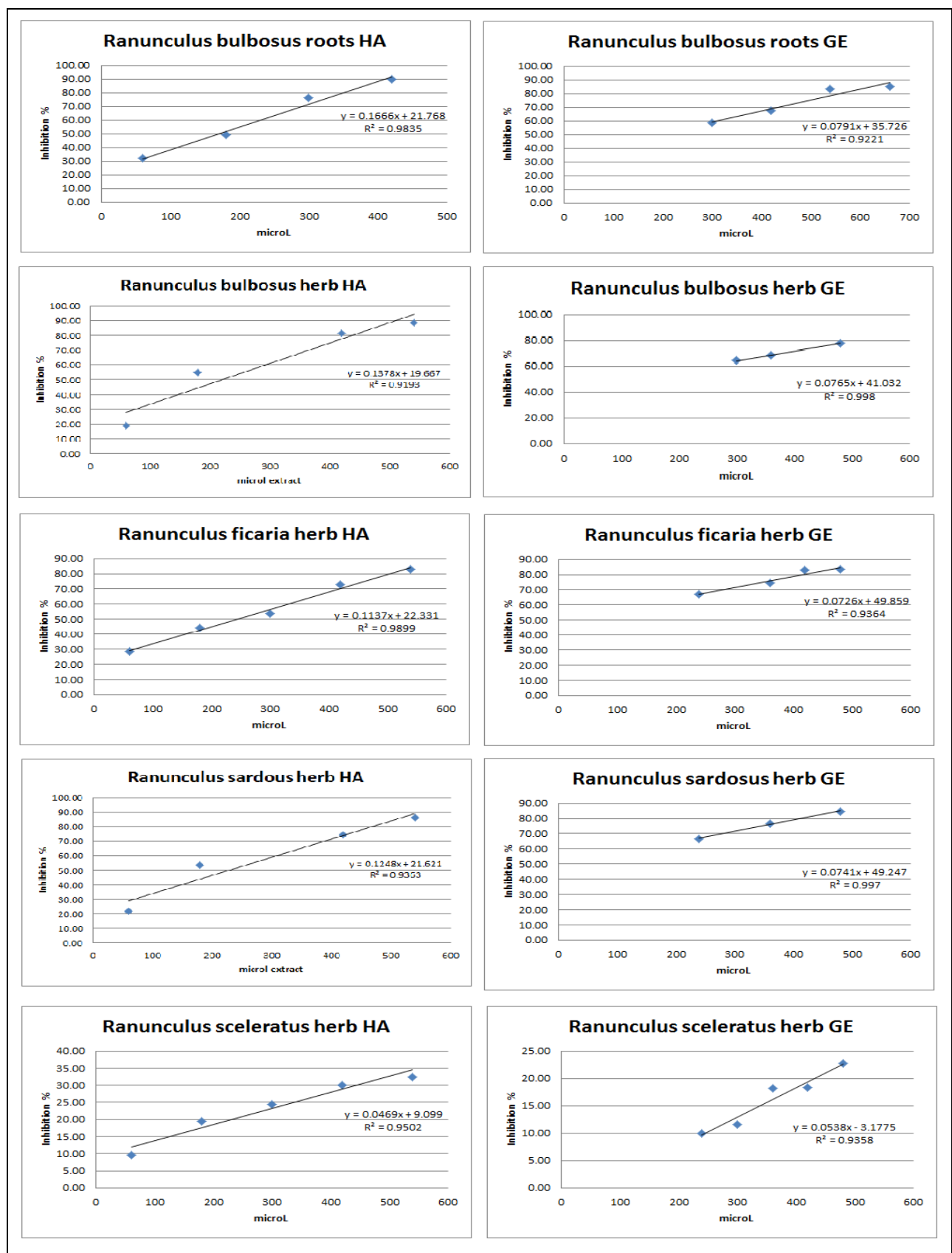

Figure 7. The inhibition curves of Ranunculus extracts obtained by DPPH method 


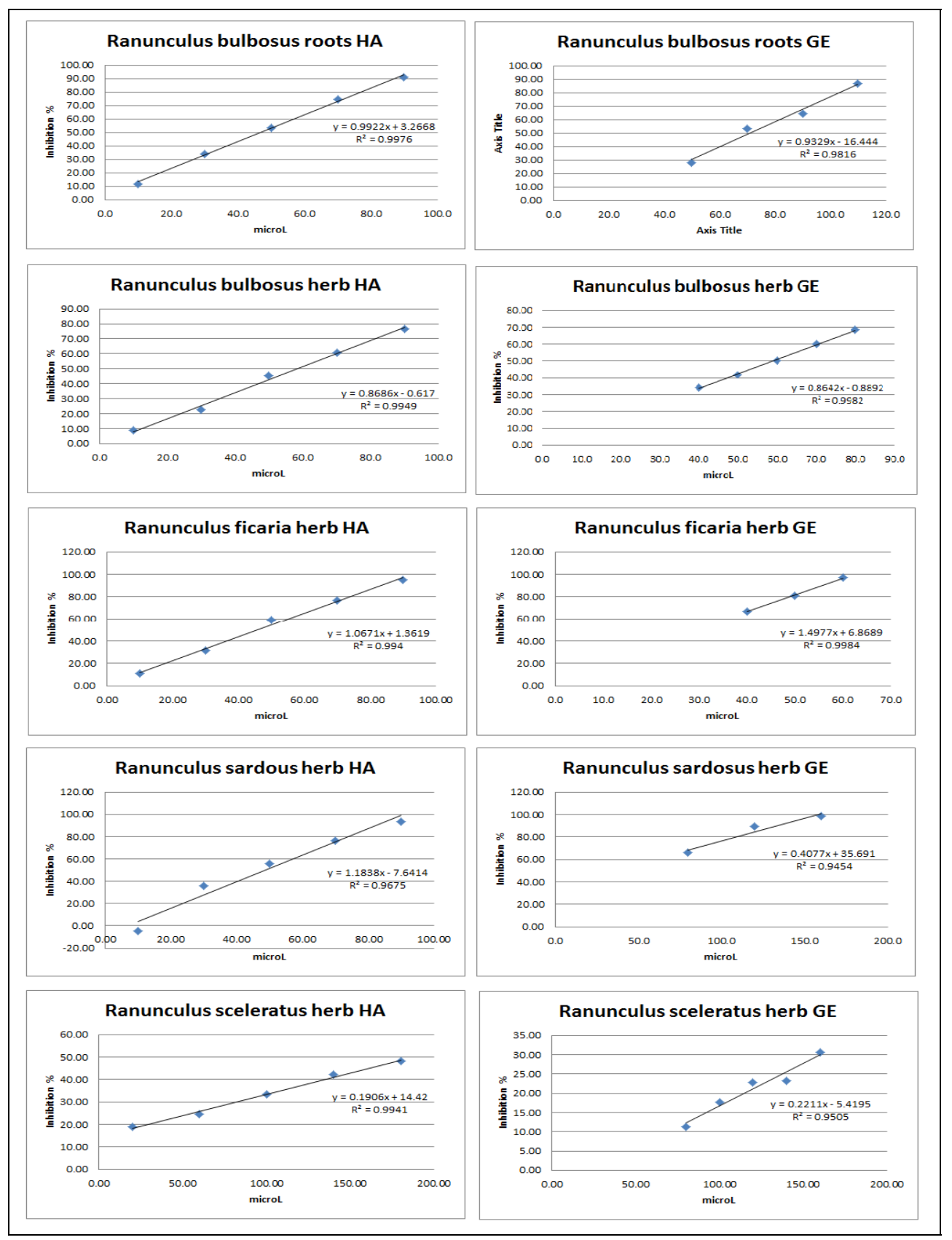

Figure 8. The inhibition curves of Ranunculus extracts obtained by TEAC method 
It can be observed that all methods indicate as the Ranunculus species with less antioxidant activity the $R$. sceleratus, both extracts from this herb having very small trolox equivalent (TE) or high $\mathrm{IC}_{50}$ values. The DPPH and TEAC methods indicates as the extracts with most important antioxidant activities the GE extracts from $R$. ficaria and $R$. sardous. According to FRAP, CUPRAC and SNP methods the extracts with most significant antioxidant activity are the GE herb extracts from $R$. bulbosus and $R$. ficaria, but also the $R$. bulbosus roots GE extract has important radical scavaneging effect.

If we compare the Ranunculus extracts antioxidant effect with those of a standard antioxidant like trolox, we can observe that the $R$. ficaria herb GE $\left(\mathrm{IC}_{50}=28.8 \mu \mathrm{l}\right)$ have almost similar antioxidant activity like the trolox $\left(\mathrm{IC}_{50}=17.4 \mu \mathrm{g}\right)$ according the TEAC method and a more significant activity according DPPH method, where the extract has $\mathrm{IC}_{50}=1.9 \mu \mathrm{l}$ and the trolox $\mathrm{IC}_{50}=50.4 \mathrm{~g}$.

It can not be found a direct or liniar correlation between the polyphenols (flavonoids and phenolic acids) content and the obtained antioxidant capacity, meaning that probably also other bioactive compounds classes will contribute to the Ranunculus species antioxidant effect.

\section{CONCLUSIONS}

In the bibliographic references cannot be found data about these Ranunculus species polyphenols or antioxidant activity, due by this fact these results seem to be the first regarding these bioactive compounds of these vegetal materials.

The study revealed that even if in GE extracts the flavonoids or phenolic acids content is mostly lower than in HA extracts the antioxidant activity is higher leading us to conclude that it is possible that these extracts to have a better therapeutic potential.

Despite the fact that the medicinal species from Ranunculus genus is $R$. bulbosus and the part of the plant used in therapy is the root, this study highlights that the herb of different Ranunculus species present a better antioxidant activity, mainly $R$. ficaria and $R$. sardous near $R$. bulbosus. The similar polyphenol profile of all studied Ranunculus species leads us to conclude that can be possible to use each of them to replace the other. To be sure about this must be made also an evaluation on anemonin and protoanemonin content, compounds that indicates these species toxicity. 


\section{EXPERIMENTAL SECTIONS}

\section{Extracts preparation}

The plants were harvested from Arad county, Romania. There were prepared two types of extracts: hydroalcoholic (HA) and glycerol-ethanol (GE).

Mother tinctures were prepared from fresh plant by maceration with $70 \%$ vol. ethanol. It was kept at room temperature for 10 days, shaking 3-4 times a day. The extractive liquid was decanted and the residue pressed. The ratio of the mass of the plant product to the extraction solvent was $1: 10(\mathrm{~m} / \mathrm{m})$.

The glycerol-ethanol extracts were obtained by maceration the fresh vegetal material with a $1: 1$ mixture of $96 \%$ vol. ethanol and glycerol, using an extraction ratio of $1: 20(\mathrm{~m} / \mathrm{m})$ ratio. They were kept at room temperature for 20 days, after which they were filtered.

\section{Antioxidant activity DPPH method}

DPPH method is based on the change in color of the 2,2-diphenyl1-picrylhydrazyl free radical, which is violet, in presence of an antioxidant when the above-mentioned radical is reduced and the color is turn on yellow. This color change can be easily correlated with the antioxidant power by a spectrophotometric determination.

The antioxidant activity was performed at $517 \mathrm{~nm}$. At $5 \mathrm{ml}$ of $25 \mathrm{mM}$ DPPH solution in methanol is added $5 \mathrm{ml}$ of samples having different antioxidant quantities $(60,180,240,300,360,420,480,540,600$ and 660 $\mu \mathrm{l})$. All mixtures were incubated for 30 minutes at $40 \mathrm{C}$ degrees. There was prepared in the same manner also a reference solution using $5 \mathrm{ml} 25 \mathrm{mM}$ DPPH solution and $5 \mathrm{ml}$ methanol. As blank solution was used methanol. For each antioxidant quantity were determined the free DPPH radical inhibition percentage and from the curves built for each sample, quantity in function of inhibition percentage, were determined also the IC50 values. There was used the following formula to determine the inhibition percentage: $\% \mathrm{I}=(\mathrm{Ar}-\mathrm{As})^{*} 100 / \mathrm{Ar}$ where $\mathrm{Ar}$ is the absorbance of reference solution and $A s$ is the absorbance of the solutions with samples $[9,10]$.

\section{FRAP method}

FRAP method is based on the change in color of a complex with iron of the TPTZ radical, 2,4,6-tripyridyl-s-triazine and on reduction of the ferric ion to the ferrous iron in this complex. The color of the complex is turn from 
light yellowish-green to blue. This color change can be easily correlated with the antioxidant power by a spectrophotometric determination.

At $2.5 \mathrm{ml} 10 \mathrm{mM}$ TPTZ solution in $40 \mathrm{mM}$ hydrochloric acid is added $2.5 \mathrm{ml} 20 \mathrm{mM}$ ferric chloride solution and $25 \mathrm{ml}$ acetate buffer at $\mathrm{pH}=3.6$. This mixture is the FRAP reagent. At $x \mathrm{ml}$ sample solution were added water until $0.8 \mathrm{ml}$ and $6 \mathrm{ml}$ FRAP reagent $(x=0.02 \mathrm{ml}$ for GE extracts and $0.01 \mathrm{ml}$ for HA extracts). Blank solution was prepared using water in place of the samples. The spectrophotometric determination was performed at $593 \mathrm{~nm}$. It was determined also the antioxidant capacity by calculate the $\mu \mathrm{M}$ Trolox equivalent $/ 100 \mathrm{ml}$ extract $[10,11]$.

\section{TEAC method}

TEAC method is based on the change in color of the 2,2-azinobis(3ethyl-benzothiazoline-6 sulfonic acid), named also ABTS, free cationic radical, which is blue, in presence of an antioxidant when the above mentioned radical is reduced and the color is turn on yellowish to colorless. The cationic radical is obtained with adding of potassium persulfate solution. This color change can be easily correlated with the antioxidant power by a spectrophotometric determination.

At 1 part of $7.5 \mathrm{mM}$ ABTS solution in methanol is added 1 part of 2.6 $\mathrm{mM}$ potassium persulfate solution in water and left to stand 12 hours at dark. Than $1 \mathrm{ml}$ of this mixture was mixed with $60 \mathrm{ml}$ of methanol and used for determinations, as ABTS reagent solution. At $x \mathrm{ml}$ sample solution was added ABTS reagent solution until $6 \mathrm{ml}$ and incubated at room temperature, at dark for 2 hours $(x=10,20,30,40,50,60,70,80,90,100,110,120,140,160,180$ $\mu \mathrm{l}$ for each extract). There was prepared in the same manner also a reference solution using methanol in place of the samples. As blank solution was used methanol. The spectrophotometric determination was performed at $734 \mathrm{~nm}$. For each antioxidant quantity were determined the free ABTS radical inhibition percentage and from the curves built for each sample, quantity in function of inhibition percentage, were determined also the IC50 values. There was used the following formula to determine the inhibition percentage: $\%=(\mathrm{Ar}-$ As) ${ }^{*} 100 / A r$ where $\mathrm{Ar}$ is the absorbance of reference solution and As is the absorbance of the solutions with samples [10,12].

\section{CUPRAC method}

CUPRAC method is based on the change in color of a complex with copper of the Neocupreine, 2,9-dimethyl-1,10-phenantroline and on reduction of the copper ion (II) to the copper iron (I) in this complex. The 
color of the complex is turn from light green to reddish-orange. This color change can be easily correlated with the antioxidant power by a spectrophotometric determination.

At $1 \mathrm{ml} 7.5 \mathrm{mM}$ neocupreine solution is added $1 \mathrm{ml} 10 \mathrm{mM}$ copper chloride solution and $1 \mathrm{ml}$ ammonium acetate buffer at $\mathrm{pH}=6.8$. This mixture is the CUPRAC reagent. At $x \mathrm{ml}$ sample solution were added water until $1.1 \mathrm{ml}$ and $3 \mathrm{ml}$ CUPRAC reagent $(x=0.03 \mathrm{ml}$ for HA extracts and 0.06 $\mathrm{ml}$ for GE extracts). The mixtures were incubated at room temperature for 30 minutes. There was prepared in the same manner also a blank solution using water in place of the samples. The spectrophotometric determination was performed at $450 \mathrm{~nm}$. It was determined also the antioxidant capacity by calculate the $\mu \mathrm{M}$ Trolox equivalent $/ 100 \mathrm{ml}$ extract [13].

\section{SNP method}

The silver nanoparticles are obtained from silver nitrate at boiling and using as surface stabilizer the trisodium citrate. The method is based on reduction of the silver ion (colorless solution) to colloidal silver (pale yellow to brownish solution) with fine silver nanoparticles suspended in solution, reaction that is occur in presence of the antioxidants. This color change from pale yellow to brownish can be easily correlated with the antioxidant power by a spectrophotometric determination. At $2 \mathrm{ml}$ of SNP reagent obtained from $10 \mathrm{mM}$ silver nitrate solution and $1 \%$ trisodium citrate solution at boiling is added $\mathrm{x} \mathrm{ml}$ sample solution and water until 0.8 $\mathrm{ml}(\mathrm{x}=0.025 \mathrm{ml}$ for HA extracts and $0.05 \mathrm{ml}$ for GE extracts). The mixtures were incubated at room temperature for 30 minutes. There was prepared in the same manner also a blank solution using water in place of the samples. The spectrophotometric determination was performed at $423 \mathrm{~nm}$. It was determined also the antioxidant capacity by calculate the $\mu \mathrm{M}$ Trolox equivalent/100 $\mathrm{ml}$ extract [14].

\section{Total flavonoids assay}

The total flavonoids expressed in rutoside were determined using aluminium chloride $2.5 \%$ at $430 \mathrm{~nm}$ according to Romanian Pharmacopoeia [14]. $1 \mathrm{ml}$ from each HA extract or $2 \mathrm{ml}$ from each GE extract, excepting $R$. sardous extracts from that were taken $0.5 \mathrm{ml}$ from each, was mixed with $5 \mathrm{ml}$ of $10 \%$ sodium acetate and $3 \mathrm{ml}$ of $2.5 \%$ aluminum chloride. These mixtures were filled with methanol until $25 \mathrm{ml}$. The same quantity from each extract was mixed with $8 \mathrm{ml}$ of water and filled to $25 \mathrm{ml}$ with methanol. These mixtures were used as blank solutions. 
After 15 minutes the samples were read at $430 \mathrm{~nm}$. There were made 3 determinations and at every determination were made 3 repeated readings. The results are the average of the 3 determinations. In the same conditions were built a calibration curve in rutoside, using solutions in methanol with a concentration of 4.08 to $20.4 \mu \mathrm{g} / \mathrm{ml}$.

\section{Total phenolic acids assay}

The total phenolic acids expressed in caffeic acid were determined using phosphotungstenic reagent at $715 \mathrm{~nm}$ according to Romanian Pharmacopoeia [15]. $2 \mathrm{ml}$ from each extract, excepting the $R$. ficaria, $R$. sardous and $R$. sceleratus HA respectively $R$. sardous GE extracts from that were picked up $1 \mathrm{ml}$, was mixed with $0,5 \mathrm{ml}$ of phosphotungstenic reagent and filled with $15 \%$ sodium carbonate until $25 \mathrm{ml}$. The same amount from each extract was filled to $25 \mathrm{ml}$ with $15 \%$ sodium carbonate and used as blank solutions. After 2 minutes the samples were read at $715 \mathrm{~nm}$. There were made 3 determinations and at every determination were made 3 repeated readings. The results are the average of the 3 determinations. In the same conditions were built a calibration curve in caffeic acid, using solutions in methanol with a concentration of 4.20 to $21.0 \mu \mathrm{g} / \mathrm{ml}$.

\section{TLC conditions}

The separations were performed on silicagel plates. As standards were used methanolic solutions of: rutoside, vitexine, quercetine, chlorogenic acid and caffeic acid, each of $1.00 \mathrm{mg} / \mathrm{mL}$. On plates were applied $20 \mu \mathrm{L}$ from tinctures and $30 \mu \mathrm{l}$ from solution obtained after SPE separation of glycerol [16] from GE extract respectively $10 \mu \mathrm{L}$ from each standard solution. The samples and standard solutions were applied as bands of $2 \mathrm{~cm}$. The mobile phase was: ethyl acetate - ethyl-methyl ketone formic acid (75:20:5, v/v) and development distance was $10 \mathrm{~cm}$. After drying of plate the chromatograms were visualized at $254 \mathrm{~nm}$.

\section{REFERENCES}

1. A. Ardelean, G.Mohan, "Medicinal Flora of Romania", Ed. ALL, Bucuresti, 2008, 33.

2. L. Tongjian, X. Lingling, L. Liang, D. Huisheng, H. Xingjie, Botanical Journal of the Linnean Society of London, 2014, 174 (2), 227. 
3. W. C. Evans In: "Pharmacognosy", 14th Ed. WB Pourrat H., Texier O. and Regerat F. (1982), Use of an Saunders Company, Tronto- Sydney-Tokyo, 1996.

4. J. Bruneton, „Pharmacognosie: Phytochimie, Plantes médicinales”, $2^{\text {nd }}$ edition, Paris, 1993, 55.

5. N. Hadaruga, Chemistry Central Journal, 2012, 762.

6. S. Aslam, A. Bashir, M. Uzair, A. Subhan, International Journal of Pharmacy and Pharmaceutical Sciences, 2012, 4(5),15.

7. I. Daraban, "Diversity, bio-economic potential and preservation of flora and halophile vegetation in Campia Aradului", PhD thesis abstract, 2013.

8. H. Mei, S. Zuo, L. Ye, J. Wang S. Ma, Journal of Medicinal Plants Research, 2012, 6(10), 1821.

9. M.N. Alam, N.J. Bristi, M. Rafiquzzaman, Saudi Pharmaceutical Journal, 2013, 21, 143.

10. K. Thaipong, U. Boonprakob, K. Crosby, L. Cisneros-Zevallos, D. Hawkins Byrne, Journal of Food Composition and Analysis, 2006, 19, 669.

11. I.F.F. Benzie, J.J Strain., Analytical Biochemistry, 1996, 239, 70.

12. M.B Arnao., A.Cano, M Acosta, Food chemistry, 2001, 73, 239.

13. M.Ozyurek, N. Gungor, S. Baki, K. Guclu, R. Apak, Analytical Chemistry, 2012, 84(18), 8052.

14. "Romanian Pharmacopoeia", Xth ed., Medical Publishing House Bucharest, Romania, 1993, 335.

15. "Romanian Pharmacopoeia", IXth ed., Medical Publishing House Bucharest, Romania, 1976.

16. S. Cobzac, G. Cimpan, N. Olah, S. Gocan, Journal of Planar Chromatography - Modern TLC, 1999, 12(1), 26. 